IZA DP No. 5790

Searching for the Entrepreneurial Personality: New Evidence and Avenues for Further Research

Marco Caliendo

Alexander Kritikos

June 2011 


\title{
Searching for the Entrepreneurial Personality: New Evidence and Avenues for Further Research
}

\author{
Marco Caliendo \\ $I Z A, I A B$ and DIW Berlin \\ Alexander Kritikos \\ DIW Berlin, University of Potsdam, \\ $I A B$ and IZA \\ Discussion Paper No. 5790 \\ June 2011 \\ IZA \\ P.O. Box 7240 \\ 53072 Bonn \\ Germany \\ Phone: +49-228-3894-0 \\ Fax: +49-228-3894-180 \\ E-mail: iza@iza.org
}

Any opinions expressed here are those of the author(s) and not those of IZA. Research published in this series may include views on policy, but the institute itself takes no institutional policy positions.

The Institute for the Study of Labor (IZA) in Bonn is a local and virtual international research center and a place of communication between science, politics and business. IZA is an independent nonprofit organization supported by Deutsche Post Foundation. The center is associated with the University of Bonn and offers a stimulating research environment through its international network, workshops and conferences, data service, project support, research visits and doctoral program. IZA engages in (i) original and internationally competitive research in all fields of labor economics, (ii) development of policy concepts, and (iii) dissemination of research results and concepts to the interested public.

IZA Discussion Papers often represent preliminary work and are circulated to encourage discussion. Citation of such a paper should account for its provisional character. A revised version may be available directly from the author. 


\section{ABSTRACT}

\section{Searching for the Entrepreneurial Personality: New Evidence and Avenues for Further Research}

What makes the entrepreneurial personality is the key question we seek to answer in the special issue of the Journal of Economic Psychology on "Personality and Entrepreneurship". The contributions are clustered around questions regarding the linkage between personality, socio-economic factors and entrepreneurial development. Results further explain the gender puzzle, while, at the same time, it is clear that stereotypes of what makes the ideal entrepreneur must be revisited. This conclusion is based on new insights into the effects that variables, such as risk tolerance, trust and reciprocity, the value for autonomy and also external role models, have on entrepreneurial decision making. On a more general note, it is clear that more informative longitudinal data sets at the individual level are needed in order to find conclusive answers. In an ideal world researchers would have access to data that includes personality characteristics and psychological traits, motivational factors and cognitive skills. In this respect the research community needs to find new ways to collect these data and make them available for entrepreneurship research.

JEL Classification: D81, J23, L26, M13

Keywords: entrepreneurship, personality characteristics, risk aversion, trust, autonomy

Corresponding author:

Alexander Kritikos

DIW Berlin

10108 Berlin

Germany

E-mail: akritikos@diw.de

\footnotetext{
"We would like to thank all contributors to the special issue "Personality and Entrepreneurship" of the Journal of Economic Psychology, all participants of the first workshop on entrepreneurship research at IZA (2010) in Bonn for the fruitful discussions during the workshop and all anonymous referees for their reports on the papers in the special issue. Moreover, we also like to thank Susanne Fricke and Adam Lederer for their support in preparing this editorial.
} 
There are many judgments concerning "the successful entrepreneur". Most refer to Schumpeter's theory (1942) of the "creative destruction" process as the driving force of economic development, where the entrepreneur plays a central role permanently facilitating economic and technical progress. In 2009, the Economist devoted even a report to these "global heroes". Two major insights can be derived from the report. The first is that the majority of entrepreneurs are (still) male and the second is that they are "a different breed of manager" in that entrepreneurs have different, distinct, personality characteristics from others. Putting together the elements of personality characteristics that were mentioned in the report, the following role model could be derived: Entrepreneurs in the Schumpeterian sense "take advantage of any market opportunity" they discover; they are "strongly attached to their companies”, “unusually, sometimes excessively, confident”, "highly tolerant of risk”, willing "to delegate certain tasks to trustworthy people" and they need to be able to create and maintain "social networks to succeed" (The Economist, 2009, p. 4f.).

The special issue of the Journal of Economic Psychology analyzes to what extent these characteristics drive the decision to enter entrepreneurship on the one hand and, on the other, being successful at it. It examines why the self-employment rates of women are consistently lower than those of men and it studies the influence of role models on entrepreneurial intentions. By examining these psychological and socio-economic characteristics of entrepreneurship, we also illustrate why approaches at the intersection of psychology and economics are particularly relevant for conducting entrepreneurship research. The papers in the special issue also make clear that to answer these questions, more data are needed. We need informative longitudinal data sets at the individual level in order to be able to give conclusive answers. One interesting question down the road is - once we have such data whether the results we find for industrialized countries can be extrapolated to transition economies and developing countries.

As not only The Economist noted, studies reveal (see inter alia Fairlie and Robb, 2009) that gender is a major issue: women are less likely to engage in entrepreneurship. In the first article of the special issue Verheul, Thurik, Grilo and Van der Zwan (2011) focus on the origins of these differences by distinguishing between mediation and moderation effects on the decision stages of entrepreneurship. They aim to find out whether the lower female entrepreneurial activity rate can be attributed to lower preferences of women to become entrepreneurs or whether it is related to the existence of gender differences with respect to other factors. While previous studies already investigated on moderation and mediation effects in this area (e.g. Verheul and Thurik, 2001), the present study tests for these effects within a new context where the entrepreneurial process is treated as a two-step procedure: the cognitive stage of "wanting it" and the behavioural stage of "doing it".

They aim to examine how gender influences the relationship between these two stages. The model is based on the theory of planned behaviour by Ajzen (1991), linking behavioral 
intentions to actual behaviour. By modifying Ajzen's theory, they examine the relationship between preferences and actual behaviour rather than that between intentions and actual behaviour. In addition, they allow subjective norms and attitudes to directly affect actual involvement in self-employment in order to find out whether the influence of these factors extends beyond the decision stage and is also important for the continuation of selfemployment. Verheul, et al. (2011) conclude that "given the untapped female entrepreneurial potential, it is important for policymakers to understand from where the gender differences in the perception of the entrepreneurial environment originate.”

The influence of preferences on actual involvement appears to be independent of gender although women generally have lower preferences for self-employment (mediation effect). Besides lower preferences, there is a significant 'direct' gender effect on actual selfemployment. This indicates that women have, ceteris paribus, a lower probability of becoming self-employed than men. Some support was found for moderation effects. The results further suggest that the relatively low self-employment rate of women is explained by both a relative lack of willingness and the existence of gender-specific obstacles. The independent effect of gender further points out that there must be other factors that are related to both self-employment and gender (like industry and entrepreneurial experience, household and family, skills and knowledge).

In the public view, entrepreneurs are "highly tolerant of risk". Previous research supports this judgment insofar as positive correlations between risk tolerance and the decision to become an entrepreneur were observed (see, e.g., Cramer, Hartog, Jonker, and Van Praag, 2002; Caliendo, Fossen, and Kritikos, 2009). It is also true that entrepreneurs are less risk averse than other persons, such as those who are regularly employed (Stewart and Roth, 2001; Hartog, Ferrer-i Carbonell, and Jonker, 2002). However, Chell, Harworth, and Brearley (1991) make clear that for entrepreneurial success it might be wise not to maximize the riskiness of investments. In line with that suggestion Caliendo, Fossen, and Kritikos (2010) find empirical evidence that there is no linear relationship between risk tolerance and entrepreneurial success. Their analysis confirms the hypothesis that persons with particularly low or particularly high risk attitudes survive as entrepreneurs less often than those with a medium-level risk attitude.

In this special issue, the role of risk attitudes is addressed by Willebrands, Lammers and Hartog (2011). Instead of focusing on its influence on survival, however, they analyze the relationship between risk attitudes and business performance in terms of revenue. For this investigation they use data from business owners in Nigeria. Willebrands, et al. develop an approach, inspired by Sitkin and Pablo (1992), that distinguishes between risk propensity and risk perception. By doing so, Willebrand, et al. predict that higher risk perception improves business performance, as perceiving more risks leads to preventive measures. They find robust support for this expectation: The propensity to take risk is negatively related to profits, but if 
risk perception is included in the analysis, risk propensity is no longer significant. That also means that entrepreneurs with a higher perception of the financial risk earn higher profits. Therefore, in line with very recent findings, Willebrands, et al. (2011) believe that "a successful businessman seems not to be afraid to take risks, but he is not a gambler either”.

A main driver of entrepreneurship is the need for autonomy. Stepping into selfemployment means becoming your own boss and the need for autonomy as a non-financial value becomes an important explanation when entrepreneurs make this career choice although their financial outcome might be lower when compared to alternatives. A number of empirical papers show that autonomy is an important motivator for choosing to be self-employed (among them are Carter, et al., 2003; Feldman and Bolino, 2000) and that jobs that provide autonomy are more intrinsically motivating than those that do not (Corman, et al., 1988).

In their theoretical study Croson and Minniti (2011) model, in a neoclassical framework, the trade-off between increased autonomy from self-employment and the higher income that traditional employment may offer. Psychologically orientated literature shows that the need for autonomy as an important motivator is rooted in the desire to determine one's own goals (Breaugh 1999). This is similar to self-determination theory (Ryan and Deci, 2000), which implies that autonomy leads to well-being and explains why autonomy in the work environment might be a compensator for higher incomes in a less autonomous position. In accordance with this heuristic Croson and Minitti show why individuals move to selfemployment despite the economic disadvantage of doing so, without assuming that entrepreneurs are inherently irrational or making a decision error. The authors focus on the analysis of a utility-maximization model of the individual's quit decision in the presence of an explicit preference for the autonomy resulting from self-employment.

The model demonstrates that newly self-employed individuals are willing to accept lower earnings in exchange for psychological benefits from self-employment. Their optimal launch-time guarantees that they will quit a job at a time when their income will initially be reduced. Utility maximizing individuals will leave employment in a lower-autonomy job more quickly than those in other jobs. The authors propose that an autonomy based preference for self-employment may be assumed as an alternative hypothesis to the classic hypothesis of overconfidence (see inter alia Forbes, 2005). Moreover, their approach is an important alternative to the seminal papers of Lucas (1978) and Kihlstrom and Laffont (1979). Lucas proposes a neoclassical model on entrepreneurs according to which persons with an entrepreneurial talent self-select into entrepreneurship. Kihlstrom and Laffont develop a similar model with the difference that not talent but risk attitudes are the driving force behind the decision.

A growing literature examines the relationship between personality traits and entrepreneurship (see inter alia Brandstätter, 1997; Zhao and Seibert, 2006, Rauch and Frese, 2007, or Caliendo, Fossen, Kritikos, 2011b). This research finds evidence that not only are the 
above mentioned variables of risk attitudes and need for autonomy important determinants of entrepreneurship but that other personality characteristics are important, too. However, few explore whether personality characteristics predispose individuals to benefit more from entrepreneurial training. Fairlie and Holleran (2011) focus exactly on this question and investigate whether entrepreneurship training has differential effects on individuals based on their personality characteristics.

In their study, they examine whether individuals with what is considered to be a "proentrepreneurial” personality benefit more form entrepreneurship training. Using data from a large randomized control experiment providing entrepreneurship training in the United States, they find that individuals who are more risk tolerant benefit more from entrepreneurship training in terms of business ownership and starting a business than those who are less risk tolerant. With regard to need for autonomy they find only instable evidence that this variable is important for the degree of benefit in entrepreneurial training. Other variables, such as being particularly innovative, show no influence on the effect of entrepreneurial training.

Once again, the variable of risk tolerance seems to deliver crucial information for the entrepreneurial process. From these findings some interesting conclusions on the effectiveness of entrepreneurial training programs can be derived. The indication that risk tolerant people benefit the most from such programs suggest that groups so far not targeted for entrepreneurship programs might benefit from inclusion. In particular, Fairlie and Holleran emphasize that some of the most disadvantaged groups, such as youth at-risk and individuals with a criminal background, have high levels of risk tolerance, and thus might benefit more from entrepreneurship training than from more traditional job training programs.

One of the formative pictures of entrepreneurial talent in the Schumpeterian sense is the person mercilessly taking advantage of any market opportunity. In this context, Urbig, Weitzel, Rosenkranz and Witteloostuijn (2011) ask if entrepreneurial talent could also be potentially destructive. The talent allocation model by Baumol (1990) and subsequent theoretical work (Murphy, et al. 1991, Acemoglu 1995) suggest that "talent allocates into activities which have the highest private returns, which need not have the highest social returns." The authors experimentally test Baumol's assumption that entrepreneurs, once having recognized an opportunity, exploit this opportunity independent of its productive or destructive nature. Thus, they investigate how people with entrepreneurial intent exploit risky investment opportunities with positive and negative externalities. Using macro-economic proxies for productive and unproductive activities the model was tested by previous studies (e.g. Sobel, 2008). However these studies are not able to directly analyze the entrepreneurial decision making process in a controlled environment and at the individual level.

Urbig, et al. focus on the underlying micro drivers of destructive versus productive entrepreneurial investment. This approach makes the study complementary to earlier work of Weitzel, et al. (2010), who focus on benevolent behaviour of entrepreneurial talent. Although 
Urbig, et al. support Weitzel, et al.'s previous results for entrepreneurial talent, they also show that a different picture emerges for people that have the intention to become an entrepreneur, regardless of their talent. In addition, they distinguish between entrepreneurial and general talent while analysing a richer experimental setting for entrepreneurial decision-making. Their results show that participants with higher entrepreneurial self-efficacy (entrepreneurial talent) invest more in both productive and destructive opportunities (the latter attributable to larger risk-taking). The generally talented and the entrepreneurially less talented participants, show no differences in their investment behaviour. Thus, by revealing that the destructive effect is not due to general talent, Urbig, et al. support the notion that entrepreneurial talent plays a distinctive (and potentially destructive) role in society. The most promising result of this study is that people who consider entrepreneurship to be a real occupational possibility (i.e. with entrepreneurial intent) invest less in destructive opportunities. The authors infer that risktakers or entrepreneurially talented persons are more willing to exploit destructive opportunities in wage employment than in private venture. Based on the findings of their study they furthermore conclude that selfishness deserves attention as one of entrepreneurs' distinctive personality characteristics.

Entrepreneurs are sometimes indeed considered as the selfish actor in the economy. At the same tine they also need to have the ability to create and maintain a social network - an ability which seems to be in certain contradiction to selfishness. Nevertheless, it is widely believed that creating a social network is a crucial characteristic for becoming a successful entrepreneur. However, it is difficult to directly measure such ability. The willingness to trust others and to act in a reciprocal way could be interpreted as an essential prerequisite for the development of social interaction and networks. Caliendo, Fossen and Kritikos (2011a) explore, for the first time, to what extent these variables of social cognition influence the decision making process of entrepreneurs in terms of entry and survival in self-employment. As experimental evidence from previous studies shows, trust and reciprocity are important characteristics that influence both participant behaviour in an experimental setting and the outcomes of experimental markets (Berg, Dickhaut and McCabe, 1995; Bolle, 1998; Cox, 2004).

Caliendo, et al. analyze whether the willingness to trust other people influences the probability of starting a business; whether trust, positive reciprocity, and negative reciprocity influence the exit probability of entrepreneurs; and whether the willingness to trust and to act reciprocally influences the probability of being an entrepreneur versus an employee or a manager. In line with previous expectations (see Logan, 2009) a higher level of trust, aggregately measured, significantly increases the probability of entry in self-employment. However, in further analysis of various single trust items, they also find that being aware of the negative consequences of unconditional trust increases the probability of being selfemployed. Moreover, the analysis surprisingly indicates that higher trust decreases the likelihood of being self-employed as opposed to a manager. 
When it comes to reciprocity, results are inconclusive. Positive reciprocity has no influence at all on the entrepreneurial status. One interesting result with negative reciprocity is the fact that a high willingness for revenge - the strongest form of negative reciprocity and thus detrimental for maintaining a network - increases the probability of entrepreneurial failure. In total, the authors find that the influence of these variables of social cognition is below expectations raised by experimental economics. The question remains open whether better measures for the ability to create and maintain social networks are needed or whether this ability is less important for entrepreneurial development.

The role model of the 'perfect entrepreneur' is a much discussed topic in the popular media. Most probably it raises the feeling among the majority of potential entrepreneurs that they are different from the stereotype of a 'perfect entrepreneur'. As the decision to become self-employed might also be influenced by public reports, role models are crucial. However, the occurrence, function and characteristics of role models are not widely studied. Bosma, Hessels, Schutjens, Van Praag and Verheul (2011) fill this gap by addressing the use of specific role models by entrepreneurship, in both the pre- and post-start-up phases of their companies. There are some previous studies indicating that role models matter for the decision to become an entrepreneur. For instance, there is evidence for the positive influence of parental role models (e.g. Fairlie and Robb, 2007). Networks (e.g., Klyver, et al., 2007) and peer groups (e.g. Gianetti and Simonov, 2009) influence the decision and may provide role models.

The authors conduct a study that includes face-to-face-interviews with entrepreneurs who started a business in the Netherlands. Results show that role models matter for the entrepreneurs: 54 percent of the entrepreneurs have a role model in either of the two phases and view them as influential. One third of the role model users claim that they would not have started their business without the presence of this role model. The dominant function of role models is 'learning by example'. Further important functions are 'learning by support', 'increasing entrepreneurial self-efficacy' and 'inspiration/motivation,' as predicted by social learning theory and role identification theory.

Furthermore, results show that role models compensate for a lack of entrepreneurial experience. It is interesting that entrepreneurs with better education are more likely to use a role model during the post start-up phase and there is a higher likelihood that these entrepreneurs view their role model as crucially important. Similarities and ties are also found to be relevant. Entrepreneurs and their role models resemble each other in terms of the characteristics, which facilitate the role identification, i.e. gender, sector and nationality. In terms of human capital and firm performance, the individuals behind the role models are older and have much larger firms than their users. Additionally, results show that 'weak ties' dominate 'strong ties'. Icons - such as those usually described in newspaper reports - are seldom considered as role models for entrepreneurs, suggesting that role models tend to be 
next-door examples. Last, but not least, as Bosma, et al. clearly point out, that gender is among the factors determining the choice of role models. This closes the circle, returning to the first contribution of this special issue, which focuses on the origins of gender differences.

The contributions to this special issue are clustered around questions regarding the link between personality traits, socio-economic factors and entrepreneurial development. Putting the pieces together, the results of the research, which will be presented in the following papers, reveal that the stereotypes we have about the ideal entrepreneur must be revisited. It makes clear that entrepreneurs seek accessible role models who can provide advice and council, and do not model themselves after famous ones that are commonly found in popular media. Moreover, some answers were given to the gender puzzle, but we still need more information to understand why women are so much less likely to be self-employed. On another note, the special issue provides several new insights on one of the most important variable related to entrepreneurship, namely risk tolerance. We see that entrepreneurs have different risk attitudes than employees, but that they do not necessarily need to be as risk tolerant as is often suggested. However, on the other hand, we also observe that the least risk adverse individuals tend to benefit the most from entrepreneurial training. In addition, entrepreneurs also need to be able to trust others, in particular at the beginning of their selfemployed career, which is, again, a risky decision. Beside the risk related analysis, results also find that there is no reason to believe that entrepreneurs mercilessly take advantage of any opportunity, no matter how harmful it is to others. Last, but not least, in view of the importance of empirical research, an extension of empirical measurement of the value of autonomy is required.

These observations suggest a number of related questions. Interesting for future investigation is the further consideration of the effect of a type-specific environment on entrepreneurship. These studies could account for the differing magnitude of the positive link between personality structure and self-employment between various groups. Another relevant field is whether, and how, role models impact the development of the firm. An important question is to what extent do role models discourage individuals from pursuing entrepreneurial opportunities (i.e. negative role models)? Future research should also focus on the effect of role model use on venture performance as a causal effect. In this context, further research for enhancing the effectiveness of entrepreneurial training and policies aimed at guiding persons successfully into self-employment are relevant.

Having addressed some important questions in this special issue makes at the same time clear, that many topics still need substantial research. Since entrepreneurship research tends to focus on industrialized economies, one crucial question is whether economies in developing countries and less innovation-driven economies are based on comparable patterns in order to see whether the results we find for industrialized countries can be extrapolated to developing economies. 
Looking at the self-employment rates between such countries shows considerable differences. For instance, while a country like Mexico has a self-employment rate of above $30 \%$, its neighbour - the US - reports self-employment rates of below $10 \%$. Three questions arise immediately out of such differences. Do the same personality characteristics play the same role in both types of countries? Are there more individuals with an entrepreneurial personality in Mexico or is the size of the "basic pool" of potential entrepreneurs the same in both countries? Which variables are apt to explain the difference between the two countries when an individual makes the decision to become self-employed - is it the mere absence of attractive alternatives as an employed or are there other reasons worth to be considered? The investigation of such differences - if existent - in the influence of psychological and socioeconomic factors on the preferences to be self-employed in developing countries versus developed countries is of practical importance. The one study on risk attitudes in the present special issue rejects such differences. Reported gender differences in preferences to become an entrepreneur should also be part of this investigation. Another more general aspect could be the test of the reversed causality between perception and actual self-employment, because perception can be formed on the basis of experience with self-employment.

Clearly, this research will be possible only if there is access to high-quality longitudinal data at an individual level. We need informative surveys that include information on all kinds of personality characteristics and psychological traits, on motivation, cognitive skills and entrepreneurial knowledge. Evidence can be based on experimental and nonexperimental data. In an ideal world, researchers can design their own data on personal characteristics and psychological traits, on motivation, entrepreneurial skills and knowledge or on the influence of role models on decision making. Such data need to be available at more than one point in time including both pre- and post-start-up in order to judge how these characteristics influence decisions at different stages of the entrepreneurial process. In this respect the research community needs to find new ways to collect these data, if possible for industrialized countries and for developing and transition economies, as well, and make them available for entrepreneurship research. Moreover, it is increasingly important to understand whether and, if so, which traits and personality characteristics are stable over a sufficient amount of time and which characteristics are, in turn, also influenced by specific entrepreneurial outcomes such as for instance large profits or large losses. In this respect the research community needs to find new ways to collect these data and make them usable for entrepreneurship research. 


\section{References}

Acemoglu, D. (1995): Reward Structures and the Allocation of Talent, European Economic Review 39, 17-33.

Ajzen, P. (1991): The theory of planned behavior, Organizational Behavior and Human Decision Processes 24(3), 233-247.

Baumol, W. (1990): Entrepreneurship: Productive, Unproductive and Destructive, Journal of Political Economy 98, 893-921.

Berg, J., Dickhaut, J., McCabe, K. (1995): Trust, Reciprocity and Social History, Games and Economic Behavior 10, 122-142.

Bolle, F. (1998): Rewarding Trust - An Experimental Study, Theory and Decision 45, 83-98.

Bosma, N.; Hessels, J.; Schutjens, V.; Van Praag, M.; Verheul, I. (2011): Entrepreneurship and Role Models, Journal of Economic Psychology, online accessible under doi:10.1016/j.joep.2011.03.004

Brandstätter, H. (1997): Becoming an Entrepreneur - A Question of Personality Structure? Journal of Economic Psychology 18, 157-177.

Breaugh, J.A. (1999): Further investigation of the work autonomy scales: Two studies, Journal of Business and Psychology 13(3), 357-373.

Caliendo, M., F.M. Fossen, Kritikos, A.S. (2009). Risk Attitudes of Nascent Entrepreneurs New Evidence from an Experimentally-Validated Survey, Small Business Economics 32(2), 153-167.

Caliendo, M., F.M. Fossen, Kritikos, A.S. (2010). The Impact of Risk Attitudes on Entrepreneurial Survival, Journal of Economic Behavior and Organization 76, 45-63.

Caliendo, M., F.M. Fossen, Kritikos, A.S. (2011a). Trust, Positive Reciprocity, and Negative Reciprocity: Do These Traits Impact Entrepreneurial Dynamics? Journal of Economic Psychology, online accessible under doi: 10.1016/j.joep.2011.01.005

Caliendo, M., Fossen, F., Kritikos, A.S. (2011b): Personality Characteristics and the Decision to Become and Stay Self-Employed, IZA Discussion Paper No. 5566.

Carter, N.M., Gartner, W.B., Shaver, K.G., Gatewood, E.J. (2003): The career reasons of nascent entrepreneurs, Journal of Business Venturing 18, 13-39.

Chell, E., J. Harworth, and S. Brearley (1991). The search for entrepreneurial traits. In E. Chell, J. Harworth, and S. Brearley (Eds.), The Entrepreneurial Personality: Concepts, Cases and Categories, Routledge Small Business Series, 29-53. London: Thomson Learning.

Corman, J., Perles, B., Vancini, P. (1988): Motivational factors influencing high-technology entrepreneurship, Journal of Small Business Management 26(1), 36-42.

Cox, J.C. (2004). How to identify trust and reciprocity. Games and Economic Behaviour 46, 260-281 
Cramer, J., J. Hartog, N. Jonker, and C. Van Praag (2002). Low Risk Aversion Encourages the Choice for Entrepreneurchip: An Empircal Test of a Truism. Journal of Economic Behavior and Organization 48, 29-36.

Croson, D.C. and Minniti, M. (2011) Slipping the Surly Bonds: The Value of Autonomy in Self-Employment, forthcoming in Journal of Economic Psychology.

Economist (2009). Global Heroes, a Special Report on Entrepreneurship, March 14 ${ }^{\text {th }}, 2009$.

Fairlie, R. W.; Holleran, W. (2011) Entrepreneurship training, risk aversion and other personality traits: Evidence from a random experiment, Journal of Economic Psychology online accessible under doi:10.1016/j.joep.2011.02.001

Fairlie, R.W., Robb, A. (2007): Families, human capital and smaller business: Evidence from the Characteristics of Business Owners Survey, Industrial and Labor Relations Review 60(2), 225-245.

Fairlie, R.W.; Robb, A. (2009). Gender Differences in Business Performance: Evidence from the Characteristics of Business Owners Survey. Small Business Economics 33(4), 375395.

Feldman, D.C., Bolino, M.C. (2000): Career patterns of the self-employed: career motivations and career outcomes, Journal of Small Business Management 38(3), 53-68.

Forbes, D.P. (2005): Are some entrepreneurs more overconfident than others? Journal of Business Venturing 20, 623-640.

Gianetti, M., Simonov, A. (2009): Social interactions and entrepreneurial activity, Journal of Economics and Management Strategy 18(3), 665-709.

Hartog, J., A. Ferrer-i Carbonell, and N. Jonker (2002). Linking Measured Risk Aversion to Individual Chracteristics. Kyklos 55, 3-26.

Kihlstrom, Richard E. and Jean-Jacques Laffont (1979). A General Equilibrium Entrepreneurial Theory of Firm Formation Based on Risk Aversion, Journal of Political Economy 87. 719-748.

Klyver, K., Hindle, K., Schott, T. (2007): Who will be entrepreneur? How crucial mechanisms and social networks structure together influence entrepreneurial participation, Frontiers of Entrepreneurship Research 27(7), 305-320

Logan, J. (2009). Dyslexic entrepreneurs: The incidence; their coping strategies and their business skills. Dyslexia, 15, 328-346.

Lucas, Robert E. Jr. (1978). On the Size Distribution of Business Firms, Bell Journal of Economics 9, 508-523.

Murphy, K., Shleifer, A., Vishny, R. (1991): The Allocation of Talent: Implications for Growth, Quarterly Journal of Economics 106, 503-530.

Rauch, A., Frese, M. (2007): Let's put the person back into entrepreneurship research: A meta-analysis on the relationship between business owners' personality traits, business creation, and success, European Journal of Work and Organizational Psychology 16, 353385.

Ryan, R.M., Deci, E.L. (2000): Self-determination theory and the facilitation of intrinsic motivation, social development, and well-being, American Psychologist 55(1), 68-78. 
Schumpeter, J.A. (1942): Capitalism, Socialism and Democracy. Harper and Brothers, New York.

Sitkin, S. B. and Pablo, A. L. (1992) “Reconceptualizing the Determinants of Risk Behavior”, The Academy Management Review 17, 9-38.

Sobel, R.S. (2008): Testing Baumol: Institutional Quality and the Productivity of Entrepreneurship, Journal of Business Venturing 23, 641-655.

Stewart, W. and P. Roth (2001). Risk Propensity Differences Between Entrepreneurs and Managers: A Meta-Analytic Review. Journal of Applied Psychology 86, 145-153.

Urbig, D., Weitzel, U., Rosenkranz, S.; van Wittelootuijn, A. (2011): Exploiting opportunities at all cost? Entrepreneurial intent and externalities, Journal of Economic Psychology, online accessible under doi:10.1016/j.joep.2011.03.003.

Verheul, I., Thurik, A.R. (2001): Start-up capital: Does gender matter? Small Business Economics 16(4), 329-345.

Verheul, I.; Thurik, R.; Grilo, I.; Van der Zwan, P. (2011) Explaining preferences and actual involvement in self-employment: Gender and the entrepreneurial personality, Journal of Economic Psychology online accessible under doi:10.1016/j.joep.2011.02.009.

Weitzel, U., Urbig, D., Desai, S., Sanders, M., Acs, Z. (2010). The good, the bad, and the talented: Entrepreneurial talent and selfish behaviour. Journal of Economic Behavior and Organization 76, 64-81.

Willebrands, D.; Lammers, J.; Hartog, J. (2011): A successful businessman is not a gambler. Risk attitude and business performance among small enterprises in Nigeria, Journal of Economic Psychology, online accessible under doi:10.1016/j.joep.2011.03.006.

Zhao, H., Seibert, S.E. (2006): The Big-Five Personality Dimensions and Entrepreneurial Status: A Meta-Analysis Review, Journal of Applied Psychology 91, 259-271. 